\title{
Morfoanatomia comparada do talo de duas espécies de Parmotrema (Parmeliaceae, Ascomycota liquenizados) com rizinas dimórficas
}

\author{
Suzana Bissacot Barbosa ${ }^{1,3}$ e Marcelo Pinto Marcelli²
}

Recebido: 30.07.2009; aceito: 23.09.2010

\begin{abstract}
Comparative thallus anatomy of Parmotrema (Parmeliaceae, lichenized Ascomycota) with dimorphic rhizinae). Using conventional techniques for structural studies under conventional and polarizing light microscopy this work describes and compares the thallus anatomy of two Parmotrema species, Parmotrema consors and Parmotrema cf. reparatum, with dimorphic rhizinae and effigutare maculae formerly attributed to Canomaculina. The obtained data showed that the species are not anatomically similar, including the aspects of epicortex, upper cortex anatomy and the rhizinae characteristics. Parmotrema cf. reparatum is anatomically similar to the previously studied group of species of Parmotrema with reticulate maculae (formerly included in Rimelia). The typical epicortex and upper cortex polysaccharides of the group of species of Parmotrema with dimorphic rhizinne showed histochemical differentiation from those mentioned for the group of Parmotrema with reticulate maculae.
\end{abstract}

Key words: effigutare maculae, thallus anatomy

RESUMO - (Morfoanatomia comparada do talo de duas espécies de Parmotrema (Parmeliaceae, Ascomycota liquenizados) com rizinas dimórficas). Utilizando técnicas convencionais para estudos histológicos em microscopia de luz com auxílio de luz polarizada, se descreve e compara a anatomia do talo de duas espécies de Parmotrema, Parmotrema consors e Parmotrema cf. reparatum, com rizinas dimórficas e máculas efiguradas, antigamente incluídas em Canomaculina. Os dados obtidos neste estudo mostram que as duas espécies são anatomicamente distintas em relação às características do epicórtex, córtex superior e rizinas. Parmotrema cf. reparatum é anatomicamente similar ao grupo de Parmotrema com máculas reticulares (antigamente incluídas em Rimelia) previamente estudados. Os polissacarídeos típicos do epicórtex e córtex superior do grupo de espécies de Parmotrema com rizinas dimórficas possuem diferenciação histoquímica daqueles mencionados para o epicórtex e córtex superior do grupo de Parmotrema com máculas reticulares.

Palavras-chave: anatomia, máculas efiguradas

\section{Introdução}

O gênero Canomaculina Elix \& Hale foi criado como um grupo segregado do gênero Parmelina Hale e caracterizado pela superfície superior com máculas efiguradas muito evidentes, lobos arredondados, cílios furcados, superfície inferior negra ou castanha, margem totalmente rizinada ou com estreita margem nua e presença de rizinas dimórficas (rizinas longas, espessas e com ápices ramificados que ocorrem num mesmo talo com rizinas curtas, finas e simples) (Elix \& Hale 1987).
Posteriormente, Elix (1997) sinonimizou o gênero Rimeliella Kurok., o qual havia sido segregado de Parmotrema Massalongo, com o gênero Canomaculina, considerando que a diferença entre os gêneros era apenas a largura dos lobos e a coloração do córtex inferior (Kurokawa 1991, Marcelli \& Benatti 2008).

Recentemente, Canomaculina foi sinonimizado com o grande gênero Parmotrema por Blanco et al. (2005) com base em evidências morfológicas e moleculares. Os autores consideram os caracteres

1. Universidade Estadual Paulista, Instituto de Biociências, Departamento de Botânica, Caixa Postal 510, 18618-000 Botucatu, SP, Brasil

2. Instituto de Botânica, Núcleo de Pesquisa em Micologia e Liquenologia, Caixa Postal 68041, 04045-972 São Paulo, SP, Brasil

3. Autor para correspondência: suzibissacot@yahoo.com.br 
utilizados para a separação desses gêneros (diferenças na largura dos lobos, máculas e tipos de cílios e rizinas) inapropriados para o reconhecimento de grupos monofiléticos em liquens. Os estudos moleculares estão de acordo com as análises morfológicas realizadas por Louwhoff \& Crisp (2000), que relatam a necessidade de mais estudos com as espécies do grande grupo parmotremóide e que poderiam ocorrer novas organizações em grupos morfológicos menores.

Este estudo teve como principal objetivo realizar um estudo anatômico comparado e detalhado do talo de duas espécies de Parmotrema com rizinas dimórficas, anteriormente colocadas em Canomaculina, procurando por parâmetros que sirvam de subsídio à taxonomia do grupo.

Os resultados apresentados aqui são parte da tese de doutorado do primeiro autor (Barbosa 2009), que visou estudar a aplicação dos dados anatômicos como auxiliares na definição taxonômica de grupos de espécies na família Parmeliaceae.

\section{Material e métodos}

O material estudado foi obtido de amostras depositadas no Herbário Científico Maria Eneyda P. Kauffmann Fidalgo (SP) do Instituto de Botânica de São Paulo, conforme a tabela 1.

Foram estudadas secções transversais e longitudinais de lobos, obtidas a partir de amostras retiradas das regiões jovem (próxima da margem) e desenvolvida (próxima ao centro) do talo. Foram preparados três blocos para cada região do talo amostrada e feitas pelo menos quatro lâminas de cada bloco.

Microscopia de luz - o material foi preparado de acordo com o protocolo estabelecido por Barbosa et al. (2009a) para estudos anatômicos de liquens da família Parmeliaceae. Amostras com $0,5 \times 1 \mathrm{~cm}$ (comp. $\times$ larg.) provenientes de material herborizado foram desidratadas em série etílica $(70 \%, 95 \%$,
$100 \%, 2$ horas cada) e incluídas em resina metacrilato $\left(\right.$ Leica $^{\circledR}$ ) por 5 horas a temperatura ambiente. Os blocos foram seccionados em micrótomo de rotação semi-automático com navalha descartável e os cortes obtidos, com 2 a $5 \mu \mathrm{m}$ de espessura, foram corados com Azul de Toluidina 0,05\%, pH 4,7 (O'Brien et al. 1965) e montados entre lâmina e lamínula com resina sintética Permount ${ }^{\circledR}$. As secções obtidas foram fotografadas em câmera Olympus acoplada a microscópio Zeiss, com e sem filtro polarizador. Foram tomadas medidas das células com auxílio de retículo de ocular.

A descrição das espécies segue o protocolo desenvolvido pelo Grupo de Estudos Liquenológicos do Instituto de Botânica, São Paulo/SP (Canêz \& Marcelli 2006), e adaptado para estudos anatômicos por Barbosa (2004).

Para as descrições anatômicas do corte transversal dos lobos das espécies neste trabalho, são consideradas as seguintes definições:

- Plectênquima: falso tecido formado por hifas entrelaçadas, interconectadas por anastomoses ou firmemente compactadas (Jahns 1973);

- Tecidos: constituído de células posicionadas lado a lado (Mauseth 1988);

- Plectênquima paliçádico: plectênquima composto por hifas paralelas com organização semelhante a paliçada (Barbosa \& Marcelli 2009)

- Paraplectênquima: plectênquima composto por hifas com paredes delgadas que perdem a aparência de hifas, com organização celular (Hawksworth et al. 1995);

- Prosoplectênquima: plectênquima de hifas com paredes espessadas, facilmente reconhecíveis (Hawksworth et al. 1995).

- Aeroplectênquima: plectênquima com grandes lacunas localizadas logo abaixo do córtex superior, na região de contato com as células de algas (Barbosa 2009).

Tabela 1. Lista dos indivíduos do gênero Parmotrema com rizinas dimórficas estudados, com respectivos coletores, número de coletor e procedência.

Table 1. List of the Parmotrema with dimorphic rhizinae studied, with their collectors, collector number and place of origin.

\begin{tabular}{llc}
\hline \multicolumn{1}{c}{ Espécies } & \multicolumn{1}{c}{ Material } & Município/Estado \\
\hline P. consors & A.A. Spielmann et al. 766 & Itirapina/SP \\
\hline P. cf. reparatum & A.A. Spielmann 93 & Sinimbu/RS \\
& A.A. Spielmann \& L.S. Canêz 692 Sinimbu/RS & Sinimbu/RS \\
\hline
\end{tabular}




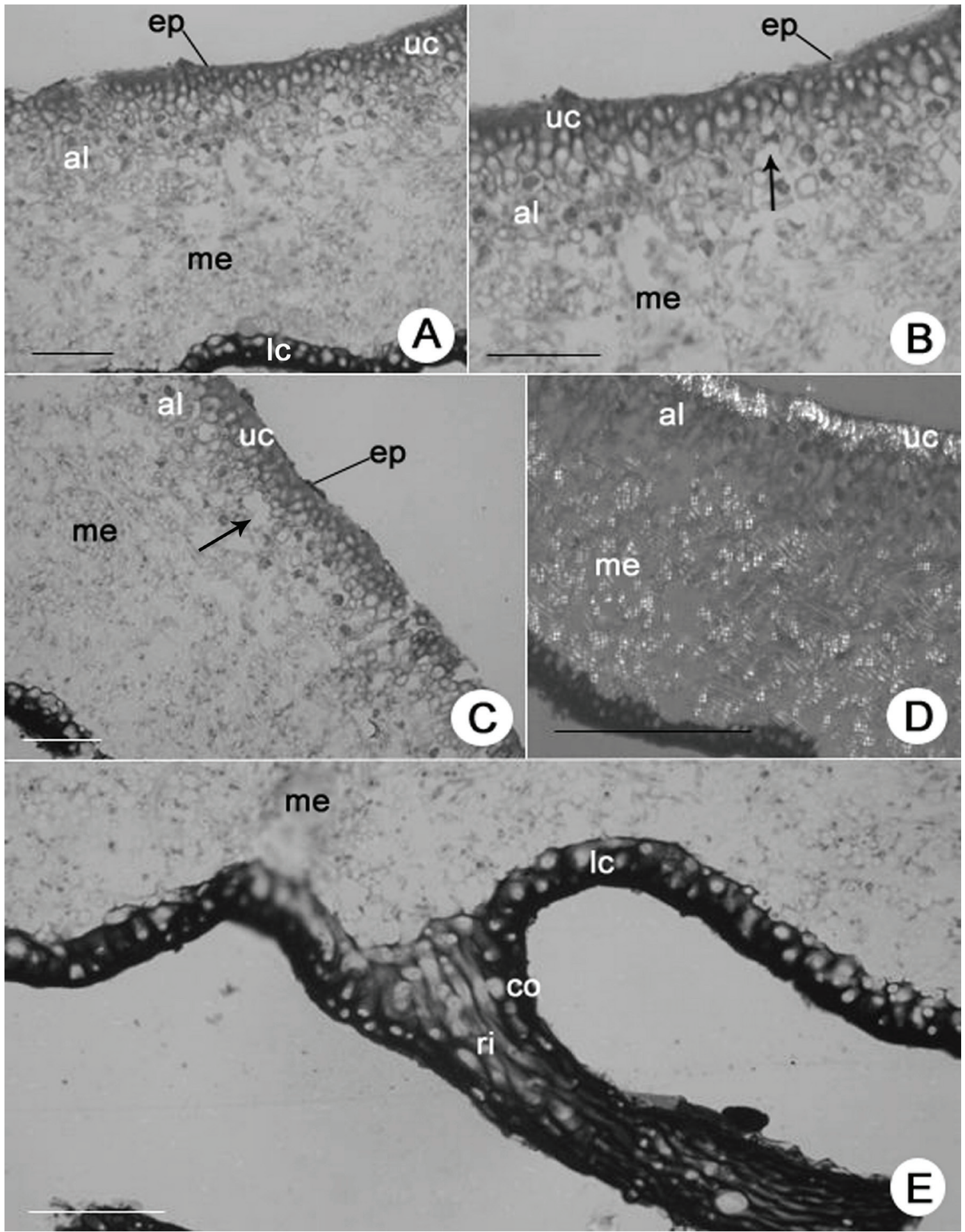

Figura 1. Anatomia do talo de Parmotrema consors. A. Secção transversal, mostrando epicórtex (ep), córtex superior (uc), camada de algas (al), medula (me) e córtex inferior (lc). B. Detalhe da região superior do talo mostrando epicórtex (ep), córtex superior (uc), lacunas (seta), camada de alga (al) e parte da medula (me). C. Detalhe mostrando epicórtex (ep), córtex superior (uc), lacunas (seta), camada de alga (al) e parte da medula (me). D. Secção transversal visualizada com auxílio de polarizador mostrando cristais presentes no córtex superior (uc) e medula (me). E. Detalhe da região inferior do talo mostrando parte da medula (me), córtex inferior (lc) e rizina (ri) recoberta por camada cortical (co). Barras $=50 \mu \mathrm{m}(\mathrm{A}, \mathrm{C}), 100 \mu \mathrm{m}(\mathrm{B}, \mathrm{D}, \mathrm{E})$.

Figure 1. Thallus anatomy of Parmotrema consors. A. Transversal section showing epicortex (ep), upper cortex (uc), algal layer (al), medulla (me) and lower cortex (lc). B. Detail of upper region of the thallus showing epicortex (ep), upper cortex (uc), lacunae (arrow), algal layer (al) and part of the medulla (me). C. Detail showing epicortex (ep), upper cortex (uc), lacunae (arrow), algal layer (al) and part of the medulla (me). D. Transversal section visualized with polarized light showing crystals on upper cortex (uc) and medulla (me). E. Detail of lower region of the thallus showing part of the medulla (me), lower cortex (lc) and rhizinae (ri) with cortical layer (co). Bars $=50 \mu \mathrm{m}(\mathrm{A}, \mathrm{C}), 100 \mu \mathrm{m}(\mathrm{B}, \mathrm{D}, \mathrm{E})$. 


\section{Resultados}

Parmotrema consors (Nyl.) Elix \& Hale, Mycotaxon 29: 239.1987.

Figura 1

Epicórtex 0,5-0,75 $\mu \mathrm{m}$ alt. bem aderido às células do córtex superior (figuras 1A, B, C). Córtex superior prosoplectênquima paliçádico. (17,5-25 $\mu \mathrm{m}$ alt.), com 1-4 céls. alt., alongadas e de parede espessada (5-) 10-12,5 × 5-7,5 $\mu \mathrm{m}$, formado a partir de hifas que partem da medula e atravessam a camada de algas; na camada mais externa de células a matriz inter-hifal reage com Azul de Toluidina produzindo uma coloração enegrecida e com a presença de cristais com brilho azulado em luz polarizada - esta reação não é observada no epicórtex e nem na camada de células mais interna em contato com as células de alga; presença de grandes lacunas (5-7,5 $\mu \mathrm{m}$ diâm.) logo abaixo do córtex superior formando um aeroplectênquima (figuras 1, B, C); máculas 12,5-25 $\mu \mathrm{m}$ larg. Camada de algas $(12,5-37,5 \mu \mathrm{m}$ alt.), com 1-3 células alt., arredondadas 7,5-12,5 $\mu \mathrm{m}$ (diâm.), conteúdo celular heterogêneo; hifas 2,5-5 $\mu \mathrm{m}$ larg., com células não muito alongadas 2,5-7,5 × 2,5-5 $\mu \mathrm{m}$; as hifas da camada de algas muitas vezes se assemelham a um colar de contas, presença de grandes lacunas 5-10 $\mu \mathrm{m}$ diâm. entre a camada de algas e a camada medular às vezes associadas às máculas (figuras $1 \mathrm{~A}, \mathrm{~B}, \mathrm{C}$ ). Medula (125-175 $\mu \mathrm{m}$ alt.), com hifas horizontais transversais e longitudinais predominantes, hifas 2,5-7,5 $\mu \mathrm{m}$ larg., com células alongadas 10-17,5 comp., presença de cristais recobrindo a parede das hifas, por toda a medula (figuras 1A, B, C, D). Sorais ausentes. Isídios ausentes. Córtex inferior prosoplectênquima, (17,5-25 $\mu \mathrm{m}$ alt.), com 1-3 células alt., arredondadas de parede espessada (5-) 12,5-17,5 ㅆm diâm., formado a partir de hifas da medula (figuras 1A, E). Rizinas dimórficas, as mais finas não são corticadas, possuem 12,517,5 $\mu \mathrm{m}$ larg., formadas por 3-7 hifas paralelas e aglutinadas cada uma com 2,5 $\mu \mathrm{m}$ larg., e as mais grossas e compridas corticadas, simples a furcadas a irregularmente ramificadas, 25-37,5 $\mu \mathrm{m}$ larg., formadas por 7-10 hifas paralelas aglutinadas, cada uma com 2,5-3,75 $\mu \mathrm{m}$ larg. (figura $1 \mathrm{E}$ ).

Material examinado: BRASIL. São PAUlo: Itirapina, Estação Experimental de Itirapina, 24III-2004, A.A. Spielmann et al. 766.(SP).
Parmotrema cf. reparatum (Stirton) Kurokawa, Bulletin of the National Science Museum Tokyo, Ser.B 27 (1): 2.2001.

Figura 2

Epicórtex 1,25-2,5 $\mu \mathrm{m}$ alt., aderido ao córtex superior (figura 2A). Córtex superior prosoplectênquima paliçádico, (17,5-37,5 $\mu \mathrm{m}$ alt.), com 3-4 células alt., alongadas e de parede espessada (5-) $10-12,5 \times 5-7,5 \mu \mathrm{m}$, formado a partir de hifas que partem da medula e atravessam a camada de alga, na camada mais externa de células a matriz inter-hifal reage com Azul de Toluidina desenvolvendo uma coloração enegrecida, com a presença de cristais com brilho azulado em luz polarizada - esta reação não é observada no epicórtex nem na camada de células mais interna em contato com as células de alga; com fissuras frequentes; presença de grandes lacunas 7,5-12,5 $\mu \mathrm{m}$ diâm. logo abaixo do córtex superior formando um aeroplectênquima (figuras $2 \mathrm{~A}, \mathrm{~B}, \mathrm{C}$, D). Máculas 12,5-25 $\mu \mathrm{m}$ larg., às vezes originando quebra. Camada de algas (12,5-25 $\mu \mathrm{m}$ alt.), com 2-4 células alt., arredondadas 5-7,5 $\mu \mathrm{m}$ diâm., conteúdo celular heterogêneo; hifas 2,5-5 $\mu \mathrm{m}$ larg., com células alongadas 7,5-10 × 2,5-5 $\mu \mathrm{m}$ (figuras $2 \mathrm{~A}$, B, C). Medula (87,5-162,5 $\mu \mathrm{m}$ alt.), hifas horizontais longitudinais e transversais predominantes, hifas 2,5-3,75 $\mu \mathrm{m}$ larg., com células finas e alongadas 1012,5 comp., sem incrustações de cristais (figuras 2A, B, C, D). Sorais ausentes. Isídios ausentes. Córtex inferior prosoplectênquima, (12,5-25 $\mu \mathrm{m}$ alt.), com 1-4 células alt., arredondadas de paredes espessadas 2,5-5 $\mu \mathrm{m}$ diâm., formado a partir de hifas medulares (figura 2A, F). Rizinas corticadas, as mais finas simples e curtas com 25-50 $\mu \mathrm{m}$ larg. formadas por 10-20 hifas paralelas e aglutinadas cada uma com 2,5 $\mu \mathrm{m}$ larg, e as mais grossas ramificadas e alongadas, com 87,5-100 $\mu \mathrm{m}$ larg., formadas por 20-30 hifas paralelas e aglutinadas cada uma com 2,5 $\mu \mathrm{m}$ larg. (figuras 2E, F).

Material examinado. BRASIL. Rio GRANDE do Sul: Sinimbu, Cava Funda, 12-II-2003, A.A. Spielmann 93 (SP); Sinimbu, Cava Funda, 5-I-2004, A.A. Spielmann \& L.S. Canêz 692, 1284 (SP).

As principais características anatômicas dos espécimes estudados estão sumarizadas na tabela 2 .

Diferenciação talina: a margem do talo dos espécimes estudados é caracterizada por possuir pequenas células do micobionte densamente compactadas, em divisão e não diferenciadas, não sendo possível a diferenciação de córtex superior e 


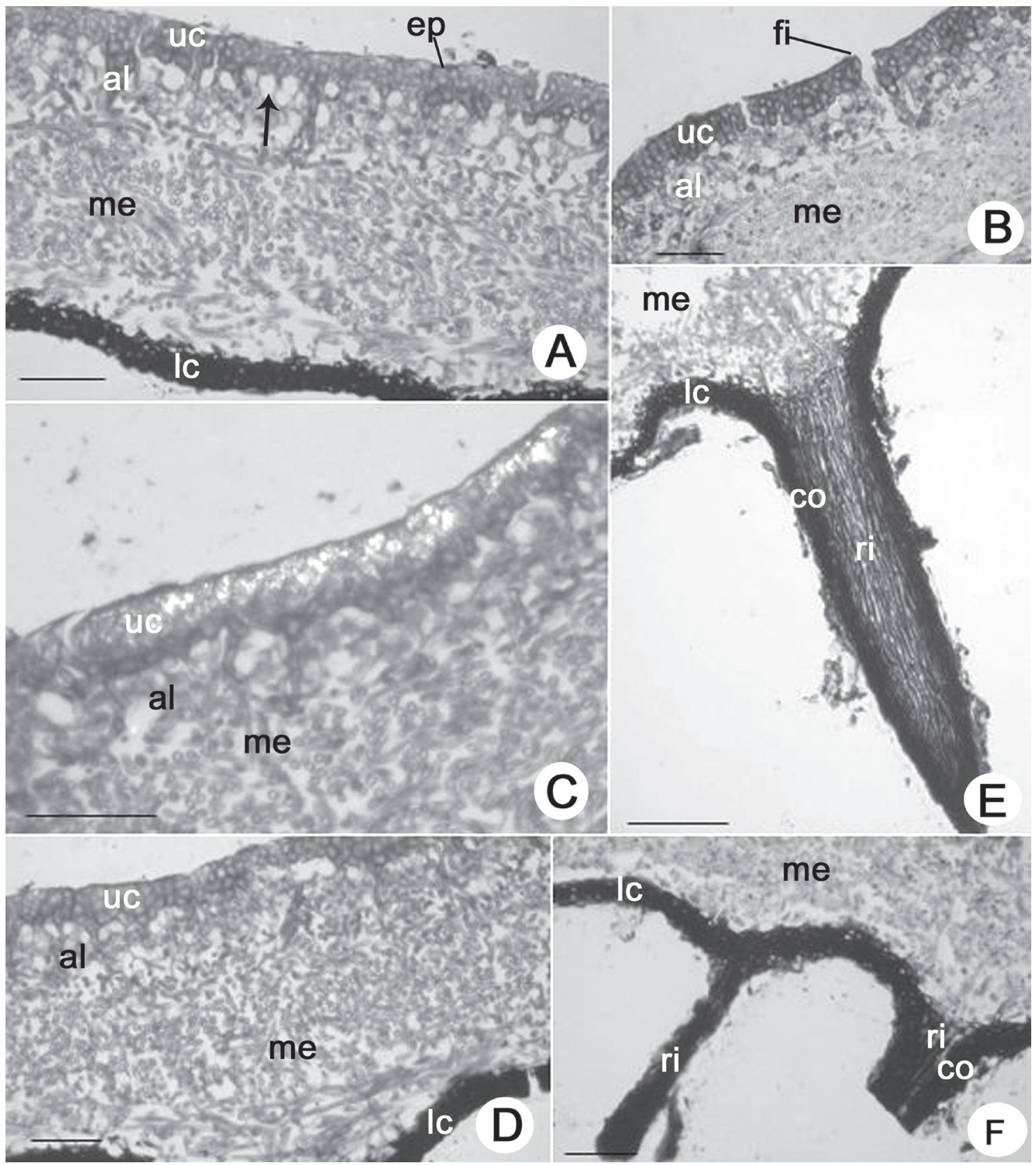

Figura 2. Anatomia do talo de Parmotrema cf. reparatum. A. Secção transversal mostrando epicórtex (ep), córtex superior (uc), lacunas (seta), camada de alga (al), medula (me) e córtex inferior (lc). B. Detalhe mostrando córtex superior (uc) com fissura (fi), camada de algas (al) e medula (me). C. Detalhe da região superior do talo visualizada com auxílio de polarizador mostrando presença de cristais no córtex superior (uc). D. Detalhe mostrando córtex superior (uc), camada de alga (al), medula (me) e córtex inferior (lc). E. Detalhe de rizina (ri) corticada (co). F. Detalhe mostrando córtex inferior (lc) e duas rizinas (ri) a mais fina sem córtex e a mais espessa corticada (co). Barras $=50 \mu \mathrm{m}$.

Figure 2. Thallus anatomy of Parmotrema cf. reparatum. A. Transversal sectionshowing epicortex (ep), upper cortex (uc), lacunae (arrow), algal layer (al), medulla (me) and lower cortex (lc). B. Detail showing upper cortex (uc) with fissure (fi), algal layer (al) and medulla (me). C. Detail of upper region of the thallus visualized with polarized light showing crystals on upper cortex (uc). D. Detail showing upper cortex (uc), algal layer (al), medulla (me) and lower cortex (lc). E. Detail of rhizinae (ri) with cortical layer (co). F. Detail showing lower cortex (lc) and two rhizines (ri), the thinner one without cortex and the thicker one with cortex (co). Bars $=50 \mu \mathrm{m}$. 
inferior; as células do micobionte são acompanhadas por células de algas (mais para o interior do talo) também em divisão. Essa região é considerada como sendo a região meristemática do talo liquênico, responsável pelo seu crescimento.

Logo após o término da região marginal iniciase a região de alongamento, que corresponde à região jovem do talo, estratificada e composta por córtex superior, camada de algas, medula e córtex inferior. Nessa região o córtex superior é composto por células maiores e arredondadas que formam um prosoplectênquima paliçádico e existe menor quantidade de células de alga em divisão, maiores que aquelas encontradas na região marginal.

A região totalmente diferenciada corresponde à área mais central do talo e é caracterizada por um córtex superior mais espesso e grandes lacunas entre a camada mais interna do córtex superior e a camada de algas, formando um aeroplectênquima. É nela que ocorre a senescência do líquen, com a presença de células mortas de ambos os biontes.

\section{Discussão}

O padrão de desenvolvimento talino interno é similar em todos os espécimes estudados e está de acordo com o observado por Honegger (1993, 2008).

As duas espécies de Parmotrema estudadas apresentam córtex superior recoberto por uma fina camada de polissacarídeos: o epicórtex (Hale 1973, 1981) (figuras 1A, B, C, 2A).

Hale (1981) considerou que as espécies da família Parmeliaceae não pseudocifeladas apresentam sempre epicórtex porado, e que essa camada de polissacarídeos apresenta a mesma constituição da matriz inter-hifal do córtex superior e se encontra acima e pouco aderida às células corticais, apresentando um aspecto ondulado em secções transversais. Nas espécies com pseudocifelas também existe uma camada de polissacarídeos, mas com constituição diferente da matriz inter-hifal e que se encontra bem aderido às células corticais (Hale 1981, Galoway \& Elix 1983).

Entretanto, nas espécies aqui estudadas o epicórtex é bem aderido às células corticais (figuras 1A, B, C, 2A), e sua visualização foi facilitada porque a matriz inter-hifal da camada mais externa de células corticais se coloriu fortemente com o Azul de Toluidina, o que não ocorreu com o epicórtex, deixando evidente a presença de uma fina camada de substância amorfa depositada acima das células corticais. Além disso, em luz polarizada foi possível a observação de um depósito de cristais com brilho azulado nessa camada mais externa de células do córtex superior (figura 1D). Não existem relatos em literatura sobre a constituição química do epicórtex e matriz inter-hifal do córtex superior nas espécies de Parmotrema com rizinas dimórficas. No entanto, os cristais depositados no córtex devem estar relacionados à presença de atranorina, que é típica no córtex dessas espécies.

Foi possível também observar a presença de grandes lacunas entre a camada mais interna do córtex superior e a camada de algas, formando um aeroplectênquima (figuras $1 \mathrm{~B}, 2 \mathrm{~A}$ ) semelhante ao observado para as espécies de Punctelia (observação pessoal).

O córtex superior em Parmotrema consors é formado por células pouco alongadas, quase arredondadas, com parede espessada, (figuras 1A, B, C). Já o córtex superior em $P$. cf. reparatum possui as células mais alongadas (figuras 2A, B). A disposição das células confere ao córtex superior uma aparência em paliçada, semelhante ao observado para as espécies de Parmotrema com máculas reticulares. No entanto, não foi verificado diferença de coloração com Azul de Toluidina na camada mais externa das células corticais daquelas espécies (observação pessoal).

São necessários estudos histoquímicos detalhados para a determinação da composição química dos polissacarídeos presentes na matriz inter-hifal e no epicórtex desses grupos distintos de Parmotrema. Modenesi (1987) realizou um estudo histoquímico com espécies de Punctelia e Parmelia e observou padrões distintos de composição química tanto do epicórtex quanto da matriz inter-hifal entre as células do córtex superior das espécies estudadas.

Parmotrema cf. reparatum apresenta fissuras freqüentes entre as células do córtex superior relacionadas aos locais de formação das máculas (figura 2B), semelhantes àquelas observadas para as espécies de Parmotrema com máculas reticulares, que são caracterizadas anatomicamente pelo córtex superior prosoplectenquimático paliçádico com fissuras freqüentes e responsáveis pelo padrão reticulado do talo. Outras características, como a espessura do epicórtex e as células corticais mais alongadas também são semelhantes àquelas relatadas para o grupo de Parmotrema com máculas reticulares indicando que $P$. cf. reparatum pode ser na realidade uma espécie nova pertencente àquele 
Tabela 2. Principais características anatômicas dos espécimes de Parmotrema estudados.

Table 2. Main anatomical features of the Parmotrema specimens studied.

\section{$\begin{array}{ll}P \text { c consors } & P \text { cf. reparatum }\end{array}$}

\begin{tabular}{|c|c|}
\hline Epicórtex & $0,5-0,75 \mu \mathrm{m}$ alt. \\
\hline $\begin{array}{l}\text { Córtex } \\
\text { superior }\end{array}$ & $\begin{array}{l}\text { prosoplectênquima paliçádico, } 1-4 \text { céls alt. } \\
(17,5-25 \mu \mathrm{m}) \text {, } \\
\text { cristais com brilho azulado em luz polarizada; } \\
\text { lacunas }(5-7,5 \mu \mathrm{m} \text { larg.) abaixo do córtex } \\
\text { superior } 1-3 \text { céls alt. }(12,5-37,5 \mu \mathrm{m}) \text {, }\end{array}$ \\
\hline $\begin{array}{l}\text { Camada de } \\
\text { algas }\end{array}$ & $\begin{array}{l}\text { grandes lacunas } 5-10 \mu \mathrm{m} \text { diâm. entre a camada } \\
\text { de algas e medula }\end{array}$ \\
\hline Máculas & $12,5-25 \mu \mathrm{m}$ larg. \\
\hline Medula & $\begin{array}{l}125-175 \mu \mathrm{m} \text { larg., hifas horizontais longitudinais } \\
\text { e transversais predominantes }\end{array}$ \\
\hline
\end{tabular}

Cristais cristais recobrindo a parede das hifas, por toda a medula

Sorédios ausentes

Isídios ausentes

Córtex

inferior

Rizinas dimórficas, as mais finas não corticadas, 12,5-17,5 $\mu \mathrm{m}$ larg., as mais grossas corticadas, 25-37,5 $\mu \mathrm{m}$ larg.
$1,25-2,5 \mu \mathrm{m}$ alt.

prosoplectênquima paliçádico, 3-4 céls alt. (17,5-37,5 $\mu \mathrm{m})$, cristais com brilho azulado em luz polarizada; com fissuras freqüentes; grandes lacunas (7,5-12,5 $\mu \mathrm{m}$ larg.) abaixo do córtex superior

2-4 céls alt. (12,5-25 $\mu \mathrm{m})$; lacunas ausentes

12,5-25 $\mu \mathrm{m}$ larg., às vezes originando quebras

87,5-162,5 $\mu \mathrm{m}$ larg., hifas horizontais longitudinais e transversais predominantes

sem incrustações de cristais

ausentes

ausentes

prosoplectênquima, 1-4 céls alt. (12,5-25 $\mu \mathrm{m})$

todas corticadas, as mais finas simples, curtas e recurvadas, $25-50 \mu \mathrm{m}$ larg., as mais grossas ramificadas e alongadas, 87,5-100 $\mu \mathrm{m}$ larg. grupo particular de espécies (antigas Rimelia) ou ainda a um terceiro grupo cujas rizinas são de dois tamanhos, porém todas corticadas. Spielmann (2005) considerou preliminarmente os espécimes estudados aqui como próximos a Canomaculina reparata, e mencionou ainda a possibilidade dela ser uma espécie nova, o que posteriormente foi confirmado pelo estudo do espécime tipo de C. reparata (Spielmann comunicação pessoal).
As rizinas apresentam dimorfismo nas duas espécies estudadas, sendo que $P$. cf. reparatum apresenta todas as rizinas corticadas; em $P$. consors as rizinas mais grossas e longas são corticadas indicando uma função de sustentação do talo, enquanto as mais finas não apresentam essa camada de células corticais (figuras 1E, 2E, F). Marcelli \& Benatti (2008) consideram que no grupo de Parmotrema com rizinas dimórficas, aquelas longas, espessas e 
de ápices ramificados são responsáveis pela fixação do talo ao substrato enquanto as rizinas curtas, finas e simples não se fixam. Barbosa et al. (2009b) relacionam a presença do córtex recobrindo as rizinas de Parmotrema tinctorum (Nylander) Hale com a função de sustentação do talo, que é grande, folioso e aderido ao substrato por poucas rizinas que têm de exercer muita força, enquanto em Parmelinopsis minarum (Vainio) Elix \& Hale, ao contrário, o talo é menor e aderido ao substrato por muitas pequenas rizinas que não necessitam dessa camada de tecido mecânico, pelo fato de cada uma delas não ser submetida a muita tração no processo de fixação.

Parmotrema consors possui cílios cespitosos e o padrão das máculas é diferente daquele encontrado em $P$. cf. reparatum; as rizinas são simples, nunca ramificadas e enroladas, como acontece em $P$. cf. reparatum. Anteriormente, $P$. consors pertencia ao gênero Canomaculina enquanto $P$. reparatum ao gênero Rimeliella. Canomaculina foi proposto por Elix \& Hale (1987) a partir de um grupo de três espécies pertencentes a Parmelina Hale, caracterizadas pelo talo adnato a fortemente adnatos, lobos estreitos e rizinas dimórficas (Elix \& Hale 1987), enquanto Rimeliella Kurok. foi proposto por Kurokawa (1991) a partir de um grupo de espécies de Parmotrema que apresentavam talo adnato a frouxo adnato, lobos largos e rizinas dimórficas, caracterizadas pela presença de rizinomorfos (pequenas rizinas simples ou rizinas em início de crescimento) sensu Hannemann (1973). Essas pequenas rizinas cobrem totalmente a superfície inferior do talo, até a margem dos lobos, e não se aderem ao substrato; mais próximo ao centro do talo são encontrados grupos de rizinas longas e grossas que se aderem ao substrato, mas que são diferentes daquelas encontradas no grupo de Parmotrema s. str. (Kurokawa 1991). No entanto, segundo Blanco et al. (2005), essas diferenças morfológicas não seriam suficientes para a diferenciação genérica.

Somados aos dados anteriormente obtidos para outros grupos de espécies, os produzidos por este estudo para o subgrupo de Parmotrema com rizinas dimórficas evidenciam que as características anatômicas do córtex superior, do córtex inferior e das rizinas são constantes dentro de um subgrupo, desde que se admita correta a interpretação de Blanco et al. (2005). Entretanto, considera-se haver indícios fortes de que o valor taxonômico das variações encontradas esteja sendo um tanto subestimado. Este estudo indica que os polissacarídeos típicos do epicórtex e córtex superior do grupo de espécies de Parmotrema com rizinas dimórficas possuem diferenciação histoquímica em relação àqueles citados para o epicórtex e córtex superior do grupo de Parmotrema com máculas reticulares. Essas características podem ser utilizadas na circunscrição de gêneros ou ao menos subgêneros em Parmeliaceae.

\section{Agradecimentos}

À CAPES pela concessão da bolsa de doutorado a S. B. Barbosa e ao CNPq por bolsa de pesquisa a M. P. Marcelli.

\section{Literatura citada}

Barbosa, S.B. 2004. Estudos anatômicos em quatro espécies de Parmeliaceae (Ascomycota liquenizados). Dissertação de Mestrado, Universidade Estadual Paulista, Botucatu.

Barbosa, S.B. 2009. Aplicabilidade taxonômica de variações anatômicas em fungos liquenizados. Tese de Doutorado, Universidade Estadual Paulista, Botucatu.

Barbosa, S.B. \& Marcelli M.P. 2009. Plectênquimas - tipos e definições. Glalia 2: 1-9.

Barbosa, S.B., Marcelli, M.P. \& Machado, S.R. 2009a. Evaluation of different protocols for anatomical studies in Parmeliaceae (lichenized Ascomycota). Micron 40: 218-225.

Barbosa, S.B., Machado, S.R. \& Marcelli, M.P. 2009b. Thallus structure and isidium development in two Parmeliaceae species (lichenized Ascomycota). Micron 40: 536-542.

Blanco, O., Crespo, A., Divakar, P.K., Elix, J.A. \& Lumbsh, H.T. 2005. Molecular phylogeny of parmotremoid lichens (Ascomycota, Parmeliaceae). Mycologia 97: 150-159.

Canêz, L.S. \& Marcelli, M.P. 2006. Gêneros de Parmeliaceae (Ascomycetes liquenizados) na localidade de Fazenda da Estrela, Vacaria, Rio Grande do Sul, Brasil. Caderno de Pesquisa, série Biologia 18: 38-81.

Elix, J.A. \& Hale, M.E. 1987. Canomaculina, Myelochroa, Parmelinella, Parmelinopsis and Parmotremopsis, five new genera in the Parmeliaceae (Lichenized Ascomycotina). Mycotaxon 29: 233-244.

Elix, J.A. 1997. The lichen genera Canomaculina and Rimeliella (Ascomycotina, Parmeliaceae). Mycotaxon 65: 475-479. 
Galloway, D.J. \& Elix, J.A. 1983. The lichen genera Parmelia Ach. and Punctelia Krog, in Australasia. New Zealand Journal of Botany 21: 397-420.

Hale, M.E. 1973. Fine structure of cortex in the family Parmeliaceae viewed with the scanning electron microscope. Smithsonian Contributions to Botany 10: 1-92.

Hale, M.E. 1981. Pseudocyphellae and pored epicortex in the Parmeliaceae: their delimitation and evolutionary significance. Lichenologist 13: 1-10.

Hannemann, B. 1973. Anhangsorgane der flechten - ihre Strukturen und ihre sustematische Verteilung. Bibliotheca Lichenologica 1: 1-123.

Hawksworth, D.L., Kirk, P.M., Sutton, B.C. \& Pegler, D.N. 1995. Dictionary of the Fungi. 8 ed. International Mycological Institute, CAB International, Oxon.

Honegger, R. 1993. Developmental biology of lichens. New Phytologist 125: 659-677.

Honegger, R. 2008. Morphogenesis. In: T.H. Nash III (ed.). Lichen biology. Cambridge University Press, Cambridge, pp. 69-93.

Jahns, H.M. 1973. Anatomy, morphology and development. In: V. Ahmadjian \& M.E. Hale (eds.). The Lichens. Academic Press, New York, pp. 3-58.
Kurokawa, S. 1991. Rimeliella, a new lichen genus related to Rimelia of the Parmeliaceae. Annals of the Tsukuba Botanical Garden 10: 1-14.

Louwhoff, S.H.J.J. \& Crisp, M.D. 2000. Phylogenetic analylis of Parmotrema (Parmeliaceae: Lichenized Ascomycotina). The Bryologist 103: 541-554.

Marcelli, M.P. \& Benatti, M.N. 2008. Espécies de Parmotrema (Parmeliaceae, Ascomycetes liquenizados) com rizinas dimórficas do litoral centrosul do Estado de São Paulo. Hoehnea 35: 7-19.

Mauseth, J.D. 1988. Plant anatomy. The Benjamin/ Cumming Publishing Company, Menlo Park.

Modenesi, P. 1987. Histochemistry and generic delimitation in Parmelia and Punctelia. Nova Hedwigia 45: 423-431.

O'Brien, T.P., Feder, N. \& McCully, M.E. 1965. Polychromatic staining of plant cell walls by toluidine blue O. Protoplasma 63: 443-478.

Spielmann, A.A. 2005. A família Parmeliaceae (fungos liquenizados) nos barrancos e peraus da encosta da Serra Geral, Vale do Rio Pardo, Rio Grande do Sul, Brasil. Dissertação de Mestrado, Instituto de Botânica, São Paulo. 